\title{
Regulatory Challenges of Brain Delivered Therapies: A Combination Product Perspective
}

\author{
Catherine Gauthier-Campbell*, Thomas Lester and Victoria Sluzky
}

BioMarin Pharmaceutical Inc, 105 Digital Drive, Novato, CA, 94949, USA

\begin{abstract}
Delivery of therapeutic agents directly to the central nervous system can be critical to address a number of diseases. Intraventricular administration of drugs has been used for over 50 years. Despite a substantial number of drugs routinely administered to the central nervous system in the course of medical practice, very few medical devices are appropriately cleared in the US for this route of administration. This review explores the regulatory challenges, the supplementary testing and more stringent acceptance criteria required for combination products and medical devices intended for CNS therapies. A case study of the recent Brineura ${ }^{\circledR}$ combination product approval is also presented.
\end{abstract}

Keywords: Intracerebroventricular; Intraventricular; FDA; Combination product; Drug administration; Central nervous system; Regulatory; Brineura

Abbreviations: CFR: Code of Federal Regulations; CNS: Central Nervous System; CSF: Cerebrospinal Fluid; Intrathecal: Administration within the Cerebrospinal Fluid at any Level of the Cerebrospinal Axis, Including Injection into the Cerebral Ventricles; Intraventricular: Administration within a Ventricle; ICV: Intracerebroventricular; FDA: U.S. Food and Drug Administration; FD\&C Act: Food, Drug, and Cosmetics Act.

\section{Introduction}

Delivery of therapeutic agents directly to the Central Nervous System (CNS) can be critical to address a haemorrhage, CNS lymphoma, glioblastoma and refractory pain. The two principal routes of administration to the Cerebrospinal Fluid (CSF) are via intrathecal lumbar puncture, or directly in a lateral ventricle of the brain.

Intraventricular, or intracerebroventricular (ICV) administration of drugs has been used for over 50 years, and delivery of therapeutic agents to the brain can be accomplished by a variety of means [1]. The most direct access requires subcutaneous implantation of an ICV access device or ventriculostomy port, such as an Ommaya reservoir [2]. Excellent comprehensive reviews on this subject have already been written $[1,3]$. Despite a long history of successful outcomes, there is only one drug specifically approved for this route of administration (per the FDA Drug Labeling Database [4]). A few therapeutic agents are approved for intrathecal administration, and depending on the drug, this may or may not include "intraventricular" administration based on the approved labeling found in Table 1. For example, in the case of DepoCyt ${ }^{ø}$ (cytarabine), which has an official FDA-approved route of administration of "intrathecal", the Dosage and Administration section of the labeling text instructs the user to administer the drug by "intraventricular or lumbar puncture". Conversely, other drugs approved for intrathecal delivery are not explicitly approved for intraventricular delivery, although many are used off-label via this route of administration.

Despite the lack of approved drugs specifically intended for intraventricular delivery, many therapies are administered to the brain in the course of routine medical practice. Drugs commonly delivered intraventricularly include: chemotherapy agents (methotrexate, mafosfamide, cytarabine, etoposide), radioisotopes, contrast agents, antimicrobials, and pain modulating agents (morphine, lidocaine, baclofen, bupivacaine, ziconotide) $[1,3,5-22]$. While there is an increasing number of drugs being administered off-label via the intraventricular route, pharmaceutical companies wishing to develop drugs for intraventricular delivery face greater challenges than drugs developed for other, more common routes of administration.

\section{Challenges with the Development of Drugs for Intraventricular Delivery}

Administration of drugs via the intraventricular route poses numerous challenges. Firstly, surgical implantation of an ICV access device (also known as Ommaya-type reservoir and catheter, or ventriculostomy port) is required for administration. Complications associated with the procedure are described in other comprehensive reviews [3,23]. Secondly, very few disposable medical devices are appropriately cleared in the US for intraventricular administration of drugs. The vast majority of medical devices used for therapeutic drug delivery are cleared for the intravascular route only, although these devices are commonly used off-label for intrathecal and intraventricular administration. Additionally, the regulatory framework surrounding devices intended for intraventricular administration is lacking (see "regulatory considerations" below) and there are few incentives for medical device developers to enter the market (smaller market, greater risks, etc.). Consequently, drug developers find themselves responsible for finding or developing devices appropriate for intraventricular delivery of their drugs. Finally, differences exist between the testing requirements to obtain approval or clearance for drugs and medical devices intended for intraventricular versus intravascular uses. Supplementary testing, including biocompatibility and endotoxin, and more stringent acceptance criteria have been established for drugs and devices intended for delivery to the CNS. The regulatory considerations and testing requirements for devices intended for intraventricular drug administration are discussed in the following sections.

\section{Regulatory considerations}

The FDA has established a classification system for medical devices, shortly after the 1976 Medical Device Amendments to Section 201(h) of

*Corresponding author: Catherine Gauthier-Campbell, BioMarin Pharmaceutical Inc, 105 Digital Drive, Novato, CA, 94949, USA, Tel: 415-455-7534; E-mail: cacampbell@bmrn.com

Received February 13, 2018; Accepted March 01, 2018; Published March 10, 2018

Citation: Gauthier-Campbell C, Lester T, Sluzky V (2018) Regulatory Challenges of Brain Delivered Therapies: A Combination Product Perspective. Pharmaceut Reg Affairs 7: 201. doi: 10.4172/2167-7689.1000201

Copyright: (C) 2018 Gauthier-Campbell C et al. This is an open-access article distributed under the terms of the Creative Commons Attribution License, which permits unrestricted use, distribution, and reproduction in any medium, provided the original author and source are credited. 
Citation: Gauthier-Campbell C, Lester T, Sluzky V (2018) Regulatory Challenges of Brain Delivered Therapies: A Combination Product Perspective. Pharmaceut Reg Affairs 7: 201. doi: 10.4172/2167-7689.1000201

Page 2 of 7

\begin{tabular}{|c|c|c|c|c|c|}
\hline Product Brand Name & Product Generic Name & Originator & Initial Approval Date & Routes of Administration & Reference / /BLA /NDA \# \\
\hline Brineura & Cerliponase alfa & $\begin{array}{c}\text { BioMarin } \\
\text { Pharmaceutical Inc. }\end{array}$ & 04/27/2017 & Intraventricular & 761052 \\
\hline Spinraza & Nusinersen & Biogen & $12 / 23 / 2016$ & Intrathecal & 209531 \\
\hline Prialt & Ziconotide & $\begin{array}{l}\text { Jazz Pharmaceuticals } \\
\text { Inc }\end{array}$ & $12 / 28 / 2014$ & Intrathecal & 021060 \\
\hline Gablofen & Baclofen & $\begin{array}{l}\text { Mallinckrodt Inc, Brand } \\
\text { Pharmaceuticals }\end{array}$ & $11 / 19 / 2010$ & Intrathecal & 022462 \\
\hline Depocyt & Cytarabine & $\begin{array}{c}\text { Sigma Tau } \\
\text { Pharmaceuticals Inc }\end{array}$ & 04/01/1999 & Intrathecal & 021041 \\
\hline Lioresal & Baclofen & Saol Therapeutics Inc. & 06/17/1992 & Intrathecal & 020075 \\
\hline Isovue-M & lopamidol & Bracco Diagnostics Inc & 12/31/1985 & Intrathecal & 018735 \\
\hline Omnipaque & lohexol & Ge Healthcare Inc & $12 / 26 / 1985$ & $\begin{array}{l}\text { Intrathecal; Intravascular; } \\
\text { Intravenous; Oral }\end{array}$ & 018956 \\
\hline $\begin{array}{l}\text { Infumorph 200; } \\
\text { Infumorph } 500\end{array}$ & Morphine Sulfate & $\begin{array}{c}\text { West Ward } \\
\text { Pharmaceuticals Corp }\end{array}$ & 09/18/1984 & Epidural; Intrathecal & 018565 \\
\hline Indium DTPA In 111 & $\begin{array}{l}\text { Pentetate indium Disodium In } \\
111\end{array}$ & GE Healthcare Inc & 02/18/1982 & Intrathecal & 017707 \\
\hline Elliotts B & $\begin{array}{c}\text { Sodium Cation, Sodium } \\
\text { Bicarbonate, Anhydrous } \\
\text { Dextrose, Magnesium Sulfate, } \\
\text { Potassium Chloride, Calcium } \\
\text { Chloride, Sodium Phosphate }\end{array}$ & Lukare Medical Llc & 09/27/1966 & Intrathecal & 020577 \\
\hline Methotrexate & Methotrexate & Hospira Worldwide Inc & 08/10/1959 & $\begin{array}{l}\text { Intra-arterial; Intramuscular; } \\
\text { Intrathecal; Intravenous }\end{array}$ & 011719 \\
\hline
\end{tabular}

*Generic versions of the RLD are not included in this table for simplicity.

Data retrieved from FDA Label Database, 6 Apr 2017 [4]. List of drugs approved prior to 1980 may be incomplete.

Table 1. List of Reference Listed Drugs Approved for Intrathecal and Intraventricular Delivery

the Federal Food, Drug and Cosmetic Act (FD\&C Act) [24]. Every device is first assigned one of three regulatory classes is based on the level of control necessary to assure the safety and effectiveness of the device: Class I (general controls), Class II (general and special controls), and Class III (general controls and premarket approval). Devices are further classified by medical specialty panels contained in 21 CFR $862-892$, according to the description and intended use of the device. Each classified device has a 7-digit number associated with the medical specialty (e.g. 21 CFR 880.5440 - Intravascular administration set) and a three letter product code which is used on the Medical Device Listing form [25-27] (e.g. FPA - Intravascular administration set). And while most medical devices can be appropriately classified according to the pre-existing product classes, some new and innovative products are more challenging to fit into this regulatory framework. New de novo classification is required for devices that have not been previously classified under the FD\&C Act. The challenge with de novo applications is that they are automatically assigned a Class III designation, meaning the highest level of controls and regulatory requirements. Intraventricular drug administration is one of those areas where few appropriate classifications exist, and a new regulatory framework is needed.

For example, when searching for medical devices used to deliver pharmaceutical products to the brain, one would naturally gravitate to the Neurology medical specialty panel (21 CFR Part 882: Neurological Devices). Interestingly, there are no established classes for devices intended for drug administration in the Neurology panel [28]. In fact, to the authors' knowledge, there is only a single product code, "PWH", which was recently introduced by FDA for infusion components that contain NRFit $^{\text {tw }}$ connectors. These connectors are specifically intended for neuraxial routes of administration and fall under the General Hospital specialty panel (21 CFR Part 880 ). Most administration sets fall under 21 CFR 880.5440 (Intravascular Administration Set) $[29,30]$. This means that administration of drugs with devices classified as above would constitute an off label use, if used in any route other than intravascular. Similarly, epidural administration sets are also not intended for intrathecal or intraventricular administration.
Interestingly, multi-purpose syringes, needles and port needles are cleared under the General Hospital specialty panel (21 CFR Part 880). This means that these devices have a broad $510(\mathrm{k})$ clearance with no restrictions to routes of administration. From a regulatory perspective, these devices are appropriately cleared or approved for intraventricular administration of medications. However, from a testing perspective, syringes and needles may not meet present day criteria for devices intended for intraventricular administration. Details of additional testing required for neuraxial devices are discussed further below.

Implanted ICV access devices, or ventriculostomy ports, are classified under the Neurological Devices specialty panel (882.5550: Central nervous system fluid shunt and components, Product Code: JXG) [31]. Despite being commercially available for over 40 years, only a handful of ports are actually cleared by the FDA for administration of medications [31]. Table 2 below illustrates the clearances of a few ICV devices: while the Codman and Integra Life Sciences devices have broad clearance for administration of any therapeutic drug, the Medtronic ICV access devices are only cleared for injection of chemotherapy agents or radioisotopes. Other types and brands of ventricular reservoirs and catheters exist; however, they are not appropriately cleared for drug administration.

The regulatory requirements for expanding the clearance or intended use of a currently marketed medical device are very extensive. Device manufacturers wishing to modify the indication for use would have to submit new premarket notification $(510(\mathrm{k}))$ or premarket approval (PMA). And for many devices that were cleared or approved a long time ago, this would require complying with today's testing standards, which are more stringent than they were decades ago. Additional testing, tighter limits and the requirement to submit a new 510(k) or PMA are significant obstacles to regulatory approvals, especially considering that the market size for devices used in intraventricular administration may be extremely small. Hence, there are very few medical devices appropriately cleared for intraventricular drug administration. 


\begin{tabular}{|c|c|c|c|}
\hline Device & Company & $510 \mathrm{~K}$ & Indication for Use \\
\hline $\begin{array}{l}\text { Ventriculostomy reservoir and } \\
\text { catheter } \\
\text { (Holter Selker, Holter Rickham or } \\
\text { Holter Salmon-Rickham type) }\end{array}$ & $\begin{array}{l}\text { Codman (formerly } \\
\text { J\&J, now Integra } \\
\text { LifeSciences) }\end{array}$ & K102961 & $\begin{array}{l}\text { The Ventriculostomy Reservoir Set is indicated for use to gain access to the cerebral } \\
\text { ventricles or other intracranial cavities for the purpose of diagnostic studies or therapeutic } \\
\text { drug administration with or without a shunting device. When used with the shunting device, } \\
\text { the ventriculostomy reservoir is also indicated for use as the proximal fluid pathway+ }\end{array}$ \\
\hline $\begin{array}{l}\text { Integra CSF reservoir with integral } \\
\text { connectors }\end{array}$ & Integra LifeSciences & K153041 & $\begin{array}{l}\text { The Integra CSF Reservoir provides access to the lateral cerebral ventricles via hypodermic } \\
\text { puncture for sampling and/or injection of fluids. It is useful in obtaining CSF samples for } \\
\text { cytological and chemical studies, for monitoring ventricular fluid pressure and for ventricular } \\
\text { drainage. The Convertible Integra CSF Reservoir may be utilized in hydrocephalic patients as } \\
\text { a component in systems designed to shunt CSF from the lateral ventricles into either the right } \\
\text { atrium of the heart or the peritoneum* }\end{array}$ \\
\hline CSF Ventriculostomy Reservoirs & Medtronic & $\begin{array}{c}\text { K874498 } \\
(1988)\end{array}$ & $\begin{array}{l}\text { CSF-Ventriculostomy reservoirs, when attached to ventricular catheters, provide access to } \\
\text { the lateral cerebral ventricles, to cystic tumors, and to debulked tumor cavities via hypodermic } \\
\text { puncture for the injection of chemotherapeutic agents and/or radioisotopes } \\
\text { For direct access to cerebral ventricles with the ability to be adapted to either a simple } \\
\text { ventriculostomy or a valved shunt system, injections, aspirations and intraventricular pressure } \\
\text { determinations }\end{array}$ \\
\hline
\end{tabular}

+ Indication for use statement obtained from $510(\mathrm{k})$ summaries found on FDA $510(\mathrm{k})$ database (https://www.fda.gov/MedicalDevices/DeviceRegulationandGuidance/ Databases/default.htm)

"Indication for use statement obtained from Instructions for Use manual for the Medtronic CSF-Ventriculostomy reservoir Part Number: 44111

"Indication for use statement obtained from FOIA request submitted to $\mathrm{CDRH}$.

Table 2: Intraventricular Access Devices Cleared for Administration of Fluids or Medications.

\section{Additional testing required for medical devices intended for intraventricular administration}

Differences exist between the testing required to obtain approval or clearance for medical devices intended for intraventricular compared to intravascular uses. Additional testing, including biocompatibility and endotoxin, and more stringent acceptance criteria have been established for devices that are intended for direct or indirect contact with the CSF.

Endotoxin limits: The Bacterial Endotoxin test (BET) is an assay to detect or quantify endotoxins from Gram-negative bacteria, generally conducted using amoebocyte lysate from the horseshoe crab (also known as the Limulus Amoebocyte Lysate (LAL) test). Endotoxin limits for drugs and medical devices that come into contact with the human body (direct or indirect) are typically established according to USP or AAMI standards [32-34]. Specifically, the endotoxin limit for parenteral drugs, defined on the basis of dose is calculated according to the formula below:

\section{Endotoxin limit $=\mathrm{K} / \mathrm{M}$}

$\mathrm{K}=$ threshold pyrogenic dose of endotoxin per $\mathrm{kg}$ of body weight;

$\mathrm{M}=$ maximum recommended bolus dose of product per $\mathrm{kg}$ of body weight.

The threshold (K) is 0.2 Endotoxin Units (EU)/kg for intrathecally administered drugs and $5 \mathrm{EU} / \mathrm{kg}$ body weight for all other routes of administration. Although endotoxin limits for drugs administered to the brain or ICV space are not specifically highlighted in USP $<85>$, presumably the same limit as intrathecally administered drugs applies to ICV drugs since they are delivered to the same contiguous biological fluid (cerebral spinal fluid (CSF)). If a drug is infused continuously, $\mathrm{M}$ is total dose administered in a single hour period [32].

For medical devices, the endotoxin limit for the finished device is Not More Than (NMT) $20 \mathrm{EU}$ per device or $0.5 \mathrm{EU} / \mathrm{mL}$ for intravascular use, and NMT $2.15 \mathrm{EU}$ or $0.06 \mathrm{EU} / \mathrm{mL}$ for devices in contact with cerebral spinal fluid (refer to USP $<161>$ ). As previously discussed, there are very few medical devices cleared for ICV delivery of drugs. Those devices that have general clearance, such as syringes or needles, are unlikely to be tested to the tighter endotoxin limits (2.15 EU/device) for CSF contact. Rather, they are most likely designed to meet limits for intravascular administration.
Additional challenges arise when multiple devices (e.g. an administration kit) are required (refer to USP $<161>$ ). In the situation where a set of devices are assembled and used together, the combined devices must meet the endotoxin limits, as listed above. For example, a set of 5 components assembled together to deliver drug to the CSF would need to meet the $2.15 \mathrm{EU}$ or $0.06 \mathrm{EU} / \mathrm{mL}$ limit for the system, suggesting that each individual device should ideally be less than $2.15 / 5$ $=0.43 \mathrm{EU} /$ device. The tighter limits are not necessarily achievable for certain medical devices or perhaps may fall below the limit of quantitation. Further, device manufacturers have very few incentives for testing already cleared or approved products to more stringent limits. The responsibility of additional testing lies with the drug manufacturer intending to develop an intraventricular-delivered drug.

Biocompatibility: Medical devices that come into direct or indirect contact with the human body should betested for biological compatibility with the body in order to determine the risk for potential adverse reactions. The degree of biocompatibility testing that is recommended in ISO-10993 and FDA's Guidance on ISO-10993-1, depends on the intended use of the device, including the intended anatomical location, as well as frequency and duration of exposure [35,36]. For example, an infusion line for repeated intravascular administration of drugs may have no intended direct contact with blood. Such a device would be categorized as an external communicating device, indirect blood path and prolonged duration ( $>24 \mathrm{~h}$ to $30 \mathrm{~d}$ ) as shown in Table 3. In this particular example, biological compatibility would be evaluated for the following endpoints: cytotoxicity, sensitization, irritation, acute systemic toxicity and hemocompatibility. This evaluation could be done by conducting biocompatibility testing and/or an assessment of existing knowledge and available literature.

In contrast, the same infusion line intended for administration to brain tissue would require additional testing including: subcutaneous/ subchronic toxicity, genotoxicity and implantation, as shown in Table 3.

Since there are no infusion lines actually cleared in the US with intended use for administration of drugs to the brain, the onus of bridging these gaps in biocompatibility testing rests with the manufacturer seeking to develop a drug intended for brain delivery. Similar conclusions can be drawn for administration sets, syringes, needles, filters or other devices cleared only for intravascular use or not evaluated for all biocompatibility endpoints.

Some of these gaps in biocompatibility evaluations may be bridged 


\begin{tabular}{|c|c|c|c|c|c|c|c|c|c|c|c|c|c|c|c|}
\hline & & & \multicolumn{13}{|c|}{ Biological effect } \\
\hline \multicolumn{2}{|c|}{ Nature of Body Contact } & \multirow{2}{*}{$\begin{array}{l}\text { Contact Duration } \\
\text { A - limited ( } \leq 24 \mathrm{~h}) \\
\text { B - prolonged (>24 h } \\
\text { to } 30 \mathrm{~d}) \\
\text { C - permanent (> } \\
30 \mathrm{~d})\end{array}$} & \multirow[b]{2}{*}{ 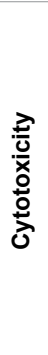 } & \multirow[b]{2}{*}{ 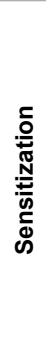 } & \multirow[b]{2}{*}{ 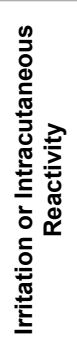 } & \multirow[b]{2}{*}{ 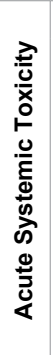 } & \multirow[b]{2}{*}{ 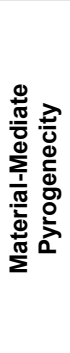 } & \multirow[b]{2}{*}{ 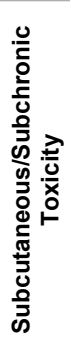 } & \multirow[b]{2}{*}{$\begin{array}{l}\frac{\lambda}{0} \\
\frac{0}{x} \\
0 \\
0 \\
0 \\
0 \\
0\end{array}$} & \multirow[b]{2}{*}{ 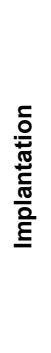 } & \multirow[b]{2}{*}{ 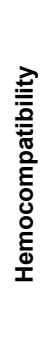 } & \multirow[b]{2}{*}{ 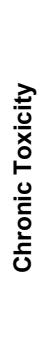 } & \multirow[b]{2}{*}{ 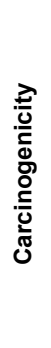 } & \multirow{2}{*}{ 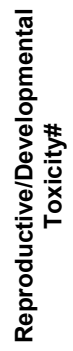 } & \multirow[b]{2}{*}{ 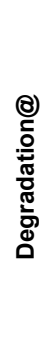 } \\
\hline Category & Contact & & & & & & & & & & & & & & \\
\hline \multirow{9}{*}{ Surface device } & \multirow{3}{*}{ Intact skin } & A & $\mathbf{x}$ & $\mathbf{x}$ & $\mathbf{x}$ & & & & & & & & & & \\
\hline & & B & $\mathbf{x}$ & $\mathbf{x}$ & $\mathbf{x}$ & & & & & & & & & & \\
\hline & & C & $\mathbf{x}$ & $\mathbf{x}$ & $\mathbf{x}$ & & & & & & & & & & \\
\hline & \multirow{3}{*}{ Mucosal membrane } & A & $\mathbf{x}$ & $\mathbf{x}$ & $\mathbf{x}$ & & & & & & & & & & \\
\hline & & B & $\mathbf{x}$ & $\mathbf{x}$ & $\mathbf{x}$ & 0 & 0 & 0 & & 0 & & & & & \\
\hline & & C & $x$ & $\mathbf{x}$ & $\mathbf{x}$ & 0 & 0 & $\mathbf{x}$ & $\mathbf{x}$ & 0 & & 0 & & & \\
\hline & \multirow{3}{*}{$\begin{array}{l}\text { Breached or } \\
\text { compromised } \\
\text { surface }\end{array}$} & A & $x$ & $\mathbf{x}$ & $\mathbf{x}$ & 0 & 0 & & & & & & & & \\
\hline & & B & $x$ & $x$ & $x$ & 0 & 0 & 0 & & 0 & & & & & \\
\hline & & C & $x$ & $\mathbf{x}$ & $\mathbf{x}$ & 0 & 0 & $x$ & $\mathbf{x}$ & 0 & & 0 & 0 & & \\
\hline \multirow{9}{*}{$\begin{array}{c}\text { External } \\
\text { communicating } \\
\text { device }\end{array}$} & \multirow{3}{*}{$\begin{array}{l}\text { Blood path, } \\
\text { indirect** }^{\star *}\end{array}$} & A & $x$ & $x$ & $x$ & $x$ & 0 & & & & $x$ & & & & \\
\hline & & B & $x$ & $x$ & $x$ & $x$ & 0 & 0 & & & $x$ & & & & \\
\hline & & C & $x$ & $x$ & 0 & $x$ & 0 & $\mathbf{x}$ & $x$ & 0 & $\mathbf{x}$ & 0 & 0 & & \\
\hline & \multirow{3}{*}{$\begin{array}{l}\text { Tissue+/bone/ } \\
\text { dentin\#\# }\end{array}$} & A & $x$ & $x$ & 0 & 0 & 0 & & & & & & & & \\
\hline & & B & $x$ & $x$ & $x$ & $x$ & 0 & $x$ & $x$ & $x$ & & & & & \\
\hline & & C & $\mathbf{x}$ & $x$ & $x$ & $x$ & 0 & $x$ & $x$ & $x$ & & 0 & 0 & & \\
\hline & \multirow{3}{*}{ Circulating blood } & A & $x$ & $x$ & $x$ & $x$ & 0 & & $0^{\wedge}$ & & $\mathbf{x}$ & & & & \\
\hline & & B & $x$ & $x$ & $x$ & $x$ & 0 & $x$ & $x$ & $x$ & $x$ & & & & \\
\hline & & C & $x$ & $\mathbf{x}$ & $x$ & $\mathbf{x}$ & 0 & $x$ & $x$ & $\mathbf{x}$ & $x$ & 0 & 0 & & \\
\hline \multirow{6}{*}{ Implant device } & \multirow{3}{*}{ Tissue+/bone } & A & $x$ & $\mathbf{x}$ & 0 & 0 & 0 & & & & & & & & \\
\hline & & B & $x$ & $x$ & $\mathbf{x}$ & $x$ & 0 & $\mathbf{x}$ & $\mathbf{x}$ & $\mathbf{x}$ & & & & & \\
\hline & & C & $x$ & $x$ & $x$ & $x$ & 0 & $x$ & $x$ & $x$ & & 0 & 0 & & \\
\hline & \multirow{3}{*}{ Blood } & A & $x$ & $x$ & $x$ & $x$ & 0 & & 0 & $x$ & $x$ & & & & \\
\hline & & B & $x$ & $x$ & $x$ & $x$ & 0 & $x$ & $x$ & $x$ & $x$ & & & & \\
\hline & & C & $x$ & $x$ & $x$ & $x$ & 0 & $x$ & $x$ & $x$ & $x$ & 0 & 0 & & \\
\hline
\end{tabular}

$X=$ ISO 10993-1:2009 recommended endpoints for consideration*

$\mathrm{O}=$ Additional FDA recommended endpoints for consideration*

Note * All X's and O's should be addressed in the biological safety evaluation, either through the use of existing data, additional endpoint-specific testing, or a rationale for why the endpoint does not require additional assessment.

Note + Tissue includes tissue fluids and subcutaneous spaces

Note ${ }^{\wedge}$ For all devices used in extracorporeal circuits

Note \# Reproductive and developmental toxicity should be addressed for novel materials, materials with a known reproductive or developmental toxicity, devices with relevant target populations (e.g., pregnant women), and/or devices where there is the probability for local presence of device materials in the reproductive organs.

Note @ Degradation information should be provided for any devices, device components, or materials remaining in contact with tissue that are intended to degrade.

**: example of an infusion line for intravascular administration of drugs with no direct contact with blood.

\#\#: example of an infusion line intended for administration of a prolonged therapy to the brain tissue.

Table 3: Biocompatibility Evaluation Endpoints Table Adapted from FDA Guidance for Industry.

by existing chemical characterization data, clinical data, marketing experience, or a risk assessment to justify appropriate testing [35]. Experience from medical devices that have been on the market for extended periods, or evaluation of materials of construction that are commonly used in medical devices can be leveraged in lieu of testing, as described in ISO 10993.

Leachables and extractables: Compatibility, suitability, leachables and extractables testing for the container closure of a drug product is a requirement for any new drug approvals in the US [37-42]. However, testing of the medical devices used for administration of the drug has not historically been required. Recently, the FDA has become increasingly concerned with leachables associated with devices used for drug administration, such as infusion bags, tubing, filters, syringes, etc. This is evidenced by FDA warnings issued regarding drug-device incompatibilities. In 2002, FDA posted a Public Health Notification warning against the use of di(2-ethylhexyl) phthalate (DEHP)-containing devices for certain patient populations [43] and published a Safety Assessment Report on the subject in 2014 [44]. In 2015, FDA warned against using the chemotherapeutic drug Treanda ${ }^{\circ}$ with administration devices containing polycarbonate or acrylonitrilebutadiene-styrene [45].

Concerns over drug-device compatibility are only enhanced in the case of drugs delivered directly to the brain or CSF. Indeed, levels of leachables and extractables for medical devices intended to be used for oral or vascular delivery may not necessarily be considered safe levels for intraventricular delivery. A toxicological risk assessment of leachables and extractables for intraventricular administration can be challenging. Often, there is no toxicology data available in the 
public domain for neuraxial routes of administration, and using oral toxicology data to extrapolate acceptable daily exposure limits for the intraventricular route can under-predict toxicities which could otherwise be a concern.

Going forward, sponsors developing drugs for intrathecal or intraventricular administration will likely be required to conduct an assessment of leachables and extractables from medical devices used in the administration of the drug. There are no FDA guidance documents on acceptable levels of leachables for drugs administered via the intraventricular route. However, USP Chapter $<661>$ has recently been updated, and new chapters are being proposed for future revisions, including USP <661.4> Plastic Medical Devices Used to Deliver or Administer Pharmaceutical Products [38]. This new chapter will provide a framework for the design and implementation of leachable assessments for delivery systems.

\section{Brineura $^{\circledR}$ Case Study}

Brineura is the first drug approved specifically for intraventricular administration in the US. It is an enzyme replacement therapy indicated for the treatment of CLN2 disease, a form of Batten disease, or neuronal ceroid lipofuscinosis type 2 (CLN2). The administration is by intraventricular infusion and requires pre-implantation of a ventricular reservoir and catheter. Every two weeks, the product is administered into the implanted reservoir through a port needle connected to a syringe via a series of infusion lines and an in-line filter. The syringe containing the drug is placed in a syringe pump to ensure slow and continuous delivery of the therapy over a period of approximately four hours. Brineura is supplied as a solution for intraventricular injection with an electrolyte flushing solution, and a separately packaged Administration Kit. The Administration Kit is approved under the Brineura product license, and cross-labelled for use with Brineura. The Administration Kit contains marketed devices in their original packaging, including: two syringes, two syringe needles, an infusion line with $0.2 \mu \mathrm{m}$ in-line filter, an extension line and a port needle.

Brineura was originally developed as a drug, not a combination product as defined in 21 CFR 3.2(e). It was not designed as a copackaged or cross-labelled biologic-device product, nor was it designed as a convenience kit. Brineura became a combination product because there are no commercially available infusion components specifically cleared for intraventricular drug administration. Indeed, common administration components are cleared under the "intravascular" or "intrathecal" or "general hospital" umbrellas, and according to FDA classification are not intended for the intraventricular route of administration. As a result, Brineura was classified as a combination product, per 21 CFR 3.2(e)(3). Being regulated as a combination product meant that the drug developer, BioMarin Pharmaceutical Inc. had to provide the necessary devices in an Administration Kit, register as a device manufacturing facility, in addition to a drug manufacturing facility, and also comply with Quality System Regulations, 21 CFR 820 as shown in Table 4 [27,46-48]. Devices included in the Administration Kit were required to meet the additional testing criteria, as described in the previous sections. FDA also required letters of authorization to access the device manufacturers' files (e.g. 510(k) Premarket Notification).

\section{Discussion}

The challenges encountered for Brineura are interesting from a regulatory perspective: despite a plethora of devices intended for the intrathecal delivery of drugs, none are specifically cleared for the intraventricular route. And although the CSF is contiguous between the intrathecal and intraventricular space, these are separate routes of administration from a U.S. regulatory perspective.

Perhaps changes to the regulatory framework are warranted in the US for medical devices intended for intraventricular delivery or other neuraxial applications (e.g. intrathecal, subarachnoid, epi, extra-, or peri-dural spaces, intratumoral, intraparenchymal). Similarly, international standards are needed to bridge the gap between intravascular and neuraxial applications. Recent updates to ISO 803696:2016 - Connectors for neuraxial applications, are an attempt to start bridging this gap. ISO 80369-6 is being implemented to prevent inadvertent misconnections between incompatible systems. Medical devices intended for neuraxial applications will have unique connector design and performance standards (NRFit) [49]. NRFit devices will start making their way to the marketplace in 2018 and California is the first state requiring facilities to make the switch [50,51]. And while implementation may be a slow process, guidelines have been drafted, and medical device companies have started developing products with neuraxial connectors [51-55]. This is a step in the right direction and will hopefully provide drug developers more options for devices intended for intraventricular administration.

Increasingly, innovative treatment and delivery approaches are being investigated to tackle the daunting needs of patients with gliomas and other brain cancers, Parkinson's, Huntington's and other neurodegenerative diseases. Updates to the regulatory framework are needed to keep pace with innovation for treating CNS diseases. As described in the preceding sections, sponsors wishing to develop drugs for intraventricular administration must consider challenges associated with combination products. The paucity of appropriately cleared devices for CNS delivery, the additional testing requirements and heightened regulatory scrutiny contribute to the challenges in gaining marketing approval in the U.S.

Proper planning prior to the initiation of clinical studies is critical to identify adequate solutions for administration of the drug. A
Key Provisions of Quality System Regulation to be Implemented if Following 21 CFR 210/211 (Current Good Manufacturing Processes For Pharmaceuticals)

\subsection{Management responsibility}

820.30 Design controls

820.50 Purchasing controls

820.100 Corrective and preventive action

820.170 Installation

820.200 Servicing
Key Provisions of Drug GMPs to be implemented if Following 21 CFR 820 (Quality System Regulation for Medical Devices)

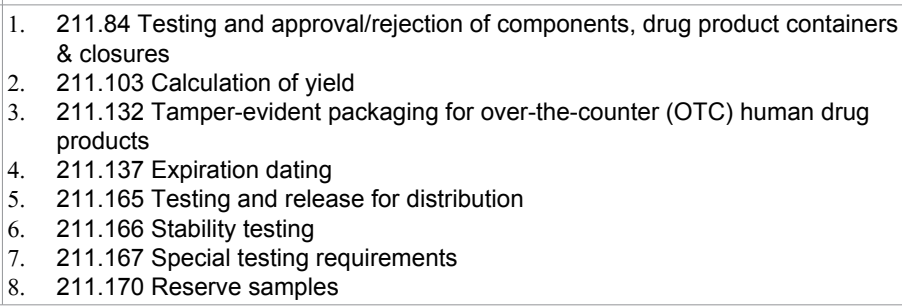

Table 4: Regulatory Requirements for Combination Product Manufacturers. 
proactive approach to development and design verification can help mitigate some of the additional requirements. Early and frequent interactions with the FDA prior to initiation of clinical studies and prior to submission of marketing applications can be helpful and are strongly recommended.

\section{Disclosures}

The views and opinions expressed in this article are those of the authors and do not necessarily reflect the official policy or position of the FDA or any agency of the US government. Examples provided, and analysis performed within this article are for illustration purposes only and not reflective of the position of any US government entity.

The authors are employed by BioMarin Pharmaceutical Inc (Novato, CA) and the company has provided funding for editorial support in the development of this manuscript.

\section{References}

1. Cook AM, Mieure KD, Owen RD, Pesaturo AB, Hatton J (2009) Intracerebroventricular Administration of Drugs. Pharmacotherapy 29: 832-845.

2. Ommaya AK (1963) Subcutaneous reservoir and pump for sterile access to ventricular cerebrospinal fluid. Lancet Lond Engl 2: 983-984.

3. Cohen-Pfeffer JL, Gururangan S, Lester T, Lim DA, Shaywitz AJ, et al. (2017) Intracerebroventricular Delivery as a Safe, Long-Term Route of Drug Administration. Pediatr Neurol 67: 23-35.

4. https://www.fda.gov/scienceresearch/bioinformaticstools/ucm289739.htm

5. Turner M, Nguyen HS, Cohen-Gadol AA (2012) Intraventricular baclofen as an alternative to intrathecal baclofen for intractable spasticity or dystonia: outcomes and technical considerations: Clinical article. J Neurosurg Pediatr 10: $315-319$

6. Ballantyne JC, Carwood CM (2005) Comparative efficacy of epidural subarachnoid, and intracerebroventricular opioids in patients with pain due to cancer. Cochrane Database Syst Rev 25: CD005178

7. Bleyer WA, Pizzo PA, Spence AM, Platt WD, Benjamin DR, et al. (1978) The Ommaya Reservoir. In Newly recognized complications and recommendations for insertion and use. 2431-2437.

8. Peyrl A, Chocholous M, Azizi AA, Czech T, Dorfer C, et al. (2014) Safety of Ommaya reservoirs in children with brain tumors: a 20-year experience with 5472 intraventricular drug administrations in 98 patients. J Neurooncol 120: 139-145.

9. Partap S, Murphy PA, Vogel H, Barnes PD, Edwards MSB, et al. (2011) Liposomal cytarabine for central nervous system embryonal tumors in children and young adults. J Neurooncol 103: 561-566.

10. Raffa RB, Pergolizzi Jr JV (2012) Intracerebroventricular opioids for intractable pain: Intracerebroventricular opioids. Br J Clin Pharmacol 74: 34-41.

11. Gwak H-S, Lee C-H, Yang HS, Joo J, Shin SH, et al. (2011) Chemoport with a noncollapsible chamber as a replacement for an Ommaya reservoir in the treatment of leptomeningeal carcinomatosis. Acta Neurochir (Wien) 153: 1971-1978.

12. Szvalb AD, Raad II, Weinberg JS, Suki D, Mayer R, et al. (2014) Ommaya reservoir-related infections: Clinical manifestations and treatment outcomes. J Infect 68: 216-224.

13. Sampath R, Wadhwa R, Tawfik T, Nanda A, Guthikonda B (2012) Stereotactic Placement of Ventricular Catheters: Does It Affect Proximal Malfunction Rates. Stereotact Funct Neurosurg 90: 97-103.

14. Mead PA, Safdieh JE, Nizza P, Tuma S, Sepkowitz KA (2014) Ommaya reservoir infections: A 16-year retrospective analysis. J Infect 68: 225-230.

15. Staquet H, Dupoiron D, Nader E, Menei P (2016) Intracerebroventricular Pain Treatment with Analgesic Mixtures including Ziconotide for Intractable Pain Pain Physician 19: E905-915.

16. Shen H, Huo Z, Liu L, Lin Z (2011) Stereotatic implantation of Ommaya reservoir in the management of brain abscesses. $\mathrm{Br} J$ Neurosurg 25: 636-640.

17. Karavelis A, Foroglou G, Selviaridis P, Fountzilas G (1996) Intraventricular administration of morphine for control of intractable cancer pain in 90 patients. Neurosurgery 39: 57-62.
18. Kramer K, Smith M, Souweidane MM (2014) Safety profile of longterm intraventricular access devices in pediatric patients receiving radioimmunotherapy for central nervous system malignancies. Pediatr Blood Cancer 61: 1590-1592.

19. Blaney SM, Balis FM, Berg S, Arndt CAS, Heideman R, et al. (2005) Intratheca Mafosfamide: A Preclinical Pharmacology and Phase I Trial. J Clin Oncol 23 1555-1563.

20. Bigner DD, Brown MT, Friedman AH, Coleman RE, Akabani G, et al. (1998) lodine-131-labeled antitenascin monoclonal antibody 81C6 treatment of patients with recurrent malignant gliomas: phase I trial results. J Clin Oncol Off J Am Soc Clin Oncol 16: 2202-2212.

21. Li KK-W, Pang JC-S, Ng H-K, Massimino M, Gandola L, et al. (2012) Feasibility and toxicity of intraventricular methotrexate for primary therapy of patients with childhood medulloblastoma treated within the hit 2000 trial. Neuro-Oncol 14 i82-i105.

22. LePage E (1993) Using a ventricular reservoir to instill amphotericin B. J Neurosci Nurs J Am Assoc Neurosci Nurses 25: 212-217.

23. Zairi F, Le Rhun E, Bertrand N, Boulanger T, Taillibert S, (2015) Complications related to the use of an intraventricular access device for the treatment of leptomeningeal metastases from solid tumor: a single centre experience in 112 patients. J Neurooncol 124: 317-323.

24. 1976 Food, Drug \& Cosmetic Act: Section 201(h) - Medical Device Amendments of 1976 - Public Law 94-295.

25. U.S. Food \& Drug Administration $C$ for $D$ and R: Device Registration and Listing

26. U.S. Food \& Drug Administration, Center for Devices and Radiological: Classify Your Medical Device.

27. Sweet BV, Schwemm AK, Parsons DM (2011) Review of the processes for FDA oversight of drugs, medical devices, and combination products. J Manag Care Pharm 17: 40-50

28. U.S. Food \& Drug Administration: Code of Federal Regulations, Title 21, Part 882: Neurological Devices.

29. U.S. Food \& Drug Administration: FDA Medical Device Databases: Product Classification.

30. 2008 U.S. Food \& Drug Administration: Guidance for Industry: Intravascular Administration Sets Premarket Notification Submissions [510(k)].

31. U.S. Food \& Drug Administration: FDA Medical Device Databases: 510(k) Premarket Notification.

32. 2011 United States Pharmacopeia (USP): Chapter <85>, Bacterial Endotoxins Test.

33. http://www.pharmacopeia.cn/v29240/usp29nf24s0_c161.htm

34. 2002 Association for the Advancement of Medical Instrumentation (AAMI): AAMI ST72: Bacterial Endotoxins - Test Methodologies, Routine Monitoring, and Alternative to Batch Testing.

35. 2016 U.S. Food \& Drug Administration: FDA Guidance for Industry: Use of International Standard ISO 10993-1, "Biological evaluation of medical devices Part 1: Evaluation and testing within a risk management process."

36. https://www.iso.org/standard/44908.htm

37. http://www.pharmacopeia.cn/v29240/usp29nf24s0_c381.html

38. https://hmc.usp.org/sites/default/files/documents/HMC/GCs-Pdfs/c661.pdf

39. http://www.pharmacopeia.cn/v29240/usp29nf24s0_c1151s34.html

40. http://www.drugfuture.com/Pharmacopoeia/usp38/data/v38332/usp38nf33s2 c1663.html

41. http://www.drugfuture.com/Pharmacopoeia/usp38/data/v38332/usp38nf33s2 c1664.html

42. https://www.gmp-compliance.org/guidelines/gmp-guideline/fda-guidance-for industry-container-closure-systems-for-packaging-human-drugs-and-biologics

43. http://www.statcorpmedical.com/avactis-images/u/06-09\%20FDA\%20 Public\%20Health\%20Notification-\%20PVC\%20Devices\%20Containing $\% 20$ the\%20Plasticizer\%20DEHP.pdf

44. https://www.fda.gov/downloads/MedicalDevices/.../UCM080457.pdf

45. https://www.fda.gov/Drugs/DrugSafety/ucm437469.htm 
Citation: Gauthier-Campbell C, Lester T, Sluzky V (2018) Regulatory Challenges of Brain Delivered Therapies: A Combination Product Perspective. Pharmaceut Reg Affairs 7: 201. doi: 10.4172/2167-7689.1000201

46. Getz MC, Shand BW, Wong O, Garrett MD (2015) Combination Products: A 40 Year Regulatory Evolution.

47. https://www.faegrebd.com/webfiles/Working\%20Through\%20the\%20U.S.\%20 Rules\%20for\%20Combination\%20Products.pdf

48. Tsourounis M, Stuart J, Smith M, Toscani M, Barone J (2015) Challenges in the Development of Drug/Device and Biologic/Device Combination Products in the United States and European Union: A Summary From the 2013 DIA Meeting on Combination Products. Ther Innov Regul Sci 49: 239-248.

49. Association for the Advancement of Medical Instrumentation (AAMI): (2017) Guideline for the implementation of medical products using small bore connectors specified in the ISO-80369 series.
50. https://www.iso.org/standard/50734.html

51. Skog J 2016 ISO 80369 is Coming-Will You Be Ready?

52. Global Enteral Device Supplier Association (GEDSA): Neuraxial Connectors (NRFitTM). Stay GEDSA

53. http://www.elcammedical.com/sites/elcam/UserContent/files/ISO_80369_ product_line_REV4_01-2017.pdf

54. https://www.smiths-medical.com/campaigns/nrfit

55. https://www.aagbi.org/sites/default/files//SO\%2080369-6\%20 Implementation\%20of\%20neuraxial\%20and\%20neural\%20devices\%20in\%20 the\%20UK.pdf 